\title{
Rare Case of Sarcomatoid Squamous Cell Carcinoma Arising in an Ovarian Mature Teratoma
}

\section{Caso raro de carcinoma espinocelular sarcomatoide que surge em um teratoma ovariano maduro}

Isabel Sofia de Sousa Pedrosa ${ }^{1}$ Filipa da Cunha Almeida Alpendre ${ }^{2}$ Rita Sousa ${ }^{3}$ Sofia Raposo Dinis ${ }^{3}$ Daniela Gomes ${ }^{3}$

\footnotetext{
${ }^{1}$ Centro Hospitalar do Baixo Vouga, Aveiro, Portugal

${ }^{2}$ Centro Hospitalar Lisboa Central, Lisboa, Portugal

${ }^{3}$ Instituto Português de Oncologia Francisco Gentil, Coimbra, Portugal
}

Address for correspondence Isabel Sofia de Sousa Pedrosa, MD, Rua Dr. António Granjo 107, 3050-225, Luso, Portugal (e-mail: sofias_pedrosa@hotmail.com).

Rev Bras Ginecol Obstet 2019;41:628-632.

\author{
Abstract \\ Keywords \\ - squamous cell \\ carcinoma \\ - ovarian mature \\ teratoma \\ - pregnant women

\section{Resumo}

\section{Palavras-chave} \\ - carcinoma de células \\ escamosas \\ - teratoma maduro \\ ovariano \\ - gestantes
}

Although mature cystic teratoma (MCT) is benign, malignant transformation (MT) occurs in $\sim 1 \%$ to $2 \%$ of all cases, and usually consists of squamous cell carcinoma (SCC), which accounts for $\sim 80 \%$ of the cases. Spindle-cell (sarcomatoid) carcinoma (SCSC) is an uncommon type of SCC, comprising up to $3 \%$ of all cases. The lack of characteristic symptoms and specific imaging findings may lead to preoperative misdiagnosis. Moreover, the clinicopathologic characteristics, the treatment, the prognostic factors and the mechanism of MT have not yet been well understood due to the rarity of such tumors, especially in women of reproductive age. The authors present a case of a 34year-old patient with 14 weeks of gestation who was diagnosed with an adnexal mass suggestive of ovarian teratoma. A laparoscopy salpingo-oophorectomy was performed after 6 months of delivery, and the histological exam revealed a sarcomatoid SCC in the MCT.

Embora o teratoma cístico maduro (MCT) seja benigno, a transformação maligna (MT) ocorre em cerca de $1 \%$ a $2 \%$ dos casos, e geralmente apresenta-se sob a forma de carcinoma espinocelular (CEC), responsável por cerca de $80 \%$ dos casos. O carcinoma (sarcomatoide) de células fusiformes (CSCF) é um tipo incomum de CEC, compreendendo até $3 \%$ de todos os casos. A falta de sintomas característicos e achados imagiológicos específicos pode levar a erros diagnósticos pré-operatórios. Além disso, as características clinico-patológicas, o tratamento, os fatores prognósticos e o mecanismo da MT ainda não são bem compreendidos devido à raridade de tais tumores, principalmente em mulheres em idade reprodutiva. Os autores apresentam um caso de uma paciente de 34 anos com 14 semanas de gestação que foi diagnosticada com uma massa anexial sugestiva de teratoma do ovário. A anexectomia laparoscópica foi realizada após 6 meses do parto, e o exame histológico revelou um CEC sarcomatoide tendo como origem um MCT. received

July 14, 2019

accepted

September 16, 2019
DOI https://doi.org/

10.1055/s-0039-1698773. ISSN $0100-7203$.
Copyright $\odot 2019$ by Thieme Revinter

Publicações Ltda, Rio de Janeiro, Brazil
License terms

(c) (1) 


\section{Introduction}

Ovarian germ-cell tumors account for $\sim 20 \%$ of all ovarian neoplasms, and for $2 \%$ of all ovarian malignancies. ${ }^{1-3}$ Mature cystic teratomas (MCTs) are the most common ovarian germcell tumors, accounting for $\sim 70 \%$ of benign ovarian tumors in women under 30 years of age, ${ }^{4-6}$ and they are composed of totipotent cells developing into well-differentiated ectodermal, endodermal, and mesodermal tissue. ${ }^{7}$ Ectodermal derivatives, which include keratinizing epidermis, sebaceous and sweat glands, hair follicles and neuroectodermal tissues, are often the most prominent. ${ }^{8}$ Mesodermal derivatives consist of muscle, bone, cartilage, fat, and occasionally teeth, whereas endodermal derivatives are represented by the thyroid, the salivary gland, the respiratory and gastrointestinal tissues. ${ }^{8}$

Although MCT is benign, malignant transformation (MT) occurs in $\sim 1 \%$ to $2 \%^{9}$ of all cases, and usually consists of squamous cell carcinoma (SCC), which accounts for approximately $80 \%$ of the cases. ${ }^{9,10}$ Squamous cell carcinomas can be ulcerative, flat, polypoid, verrucous or exophytic. ${ }^{11}$ Occasionally, SCC variants will be encountered. ${ }^{11}$ Together, these variants make up $10 \%$ to $15 \%$ of all cases of SCC, including verrucous, exophytic or papillary, spindle-cell (sarcomatoid), basaloid and adenosquamous carcinomas. ${ }^{11}$ Over the years, many terms have been applied to spindle-cell (sarcomatoid) carcinoma (SCSC), such as carcinosarcoma, pseudosarcoma and squamous cell carcinoma with pseudosarcoma, but SCSC is defined as a spindle-cell neoplasm that simulates a sarcoma and presents epithelial differentiation in both immunohistochemistry and electron microscopy. ${ }^{12}$ Spindle-cell (sarcomatoid) carcinoma is an uncommon type of squamous cell carcinoma, comprising up to $3 \%$ of all cases of SCC. ${ }^{11}$

Mature cystic teratomas with MT are usually observed in postmenopausal women with a mean age of 45 to 60 years. ${ }^{9-13}$ Other less frequent malignancies include mucinous carcinoma, adenocarcinoma arising from the respiratory ciliated epithelium, melanoma, carcinoid, thyroid carcinoma, sebaceous carcinoma, oligodendroglioma and sarcoma. ${ }^{13}$ The lack of characteristic symptoms and specific imaging findings may lead to preoperative misdiagnosis. ${ }^{14}$ Although the preoperative diagnosis of MCT of the ovary is usually achieved with the use of sonography, computed tomography (CT) and magnetic resonance imaging (MRI), MT it is usually detected incidentally postoperatively, based on detailed pathological examination. ${ }^{14}$ The optimal treatment for MT in cases of MCT is uncertain due to the rarity of the disease. ${ }^{15}$ The authors present a case of a 34year-old patient with 14 weeks of gestation who was diagnosed with an adnexal mass suggestive of ovarian teratoma. A laparoscopy salpingo-oophorectomy was performed after 6 months of delivery, and the histological exam revealed a sarcomatoid SCC in the MCT.

\section{Case Description}

A 34-year-old patient with 14 weeks of gestation (gravida 1, para 0) was referred to a gynecological consultation for an adnexal right mass. A gynecological ultrasound revealed a unilocular cystic tumor on the right ovary, with $100 \mathrm{~mm}$ in

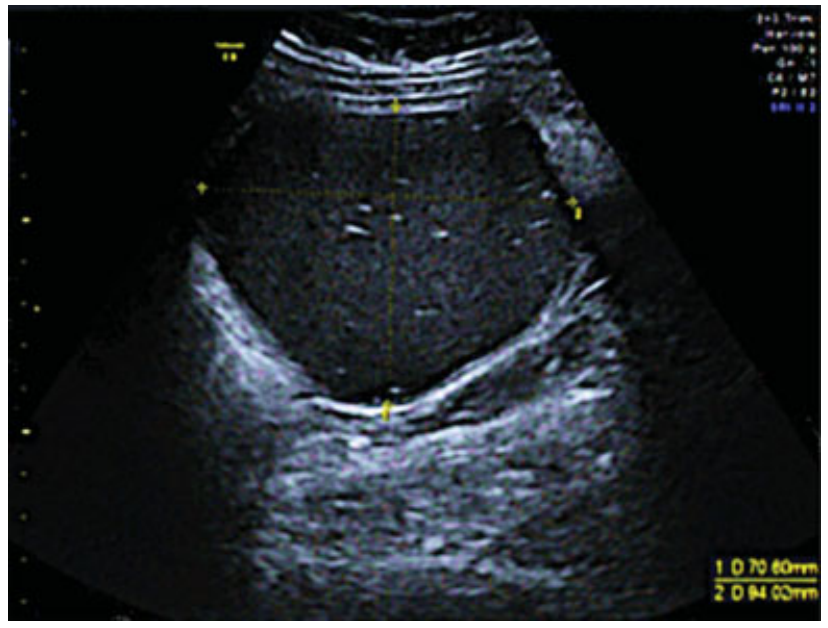

Fig. 1 Ultrasound image of the unilocular cystic tumor on the right ovary with mixed echogenicity and acoustic shadows. According to the International Ovarian Tumor Analysis (IOTA) simple rules, this adnexal mass was classified as benign. ${ }^{16}$ Source: Timmerman et al. ${ }^{16}$

size, with mixed echogenicity and acoustic shadows (- Fig. 1). ${ }^{16}$ According to the simple rules ${ }^{16}$ of the International Ovarian Tumor Analysis (IOTA) group, the cyst was classified as benign, because it had one benign feature (unilocular lesion) and no malignant features. We could also identify the so-called IOTA easy descriptors ${ }^{16}$ for dermoid cysts, such as unilocular cyst, mixed echogenicity and premenopausal woman.

Based on the imaging findings, the suspected diagnosis was right ovarian teratoma. The results of the laboratory tests revealed normal serum levels of squamous cell carcinoma antigen (SCCA), carbohydrate antigen (CA) 125, carcinoembryonic antigen (CEA), $\beta$-human chorionic gonadotropin (hCG), $\alpha$-fetoprotein (AFP), lactic dehydrogenase, and CA19-9.

The pregnancy occurred uneventfully, and the patient delivered a healthy new-born. Surgery was delayed for 6 months after delivery. The patient underwent a laparoscopic right-sided salpingo-oophorectomy. During the procedure, we identified a smooth-surfaced, spherical, cystic tumor measuring $100 \mathrm{~mm}$ in the right ovary. The uterus and left ovary were macroscopically normal. There was no capsule rupture, and the cyst was extracted with an endo-bag. The anatomopathological exam revealed the presence of a sarcomatoid SCC in an MCT (- Figs. 2 and $\mathbf{3}$ ).

To exclude distant metastasis, positron emission tomography (PET) was performed, which did not show evidence of locoregional or distant metastasis. The surgical options were fully discussed with the patient, who chose to preserve fertility. A laparotomy of staging was performed with peritoneal fluid cytology, multiple peritoneal biopsies, omentectomy, diaphragmatic dome cytology and pelvic and paraaortic lymphadenectomy. The uterus and left ovary had normal sizes, and did not present macroscopic changes. No tumor alterations were revealed in the staging, and the tumor was classified as stage I. No further treatments were administered. The patient remained asymptomatic and showed no evidence of local recurrence or systemic disease after 3 years of clinical surveillance. 


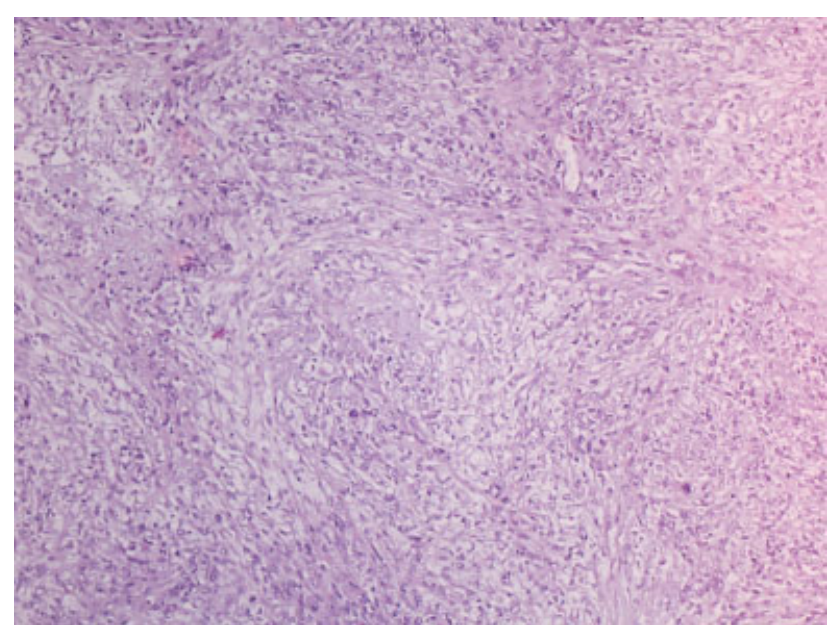

Fig. 2 Histological finding with hematoxylin and eosin staining at original magnification $\times 10$. Malignant proliferation of epithelioid and spindle cells, with a diffuse or fascicular growth pattern. The tumor was a sarcomatoid squamous cell carcinoma.

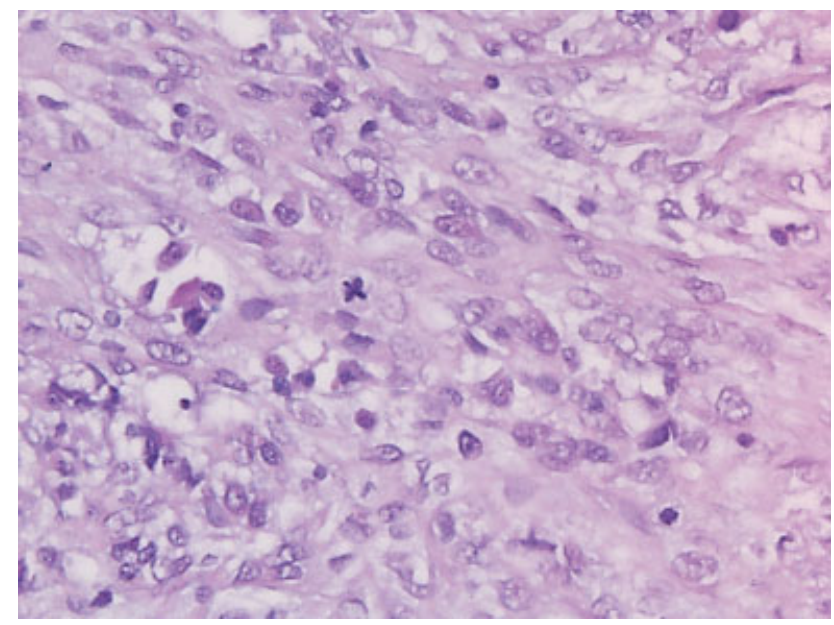

Fig. 3 Histological finding with hematoxylin and eosin staining at original magnification $\times 40$. The cells show oval nuclei with evident pleomorphism and eosinophilic cytoplasms without sharp borders. The mitotic activity was very high ( 22 mitoses $/ 10$ high-power fields). A large immunohistochemical panel (not shown) favored the diagnosis of poorly-differentiated (sarcomatoid) squamous cell carcinoma.

\section{Discussion}

In women under 30 years of age, MCTs are the most common ovarian germ-cell tumors. ${ }^{17}$ Malignant transformation in MCTs usually occurs later in life, and is reported around the fifth decade. ${ }^{3}$ Cases of SCCs arising in an MCT are uncommon, with an incidence lower than $2 \%,{ }^{10}$ but they are the most common malignancy to arise in MCTs, comprising $\sim 80 \%$ of malignancies. ${ }^{17}$ Moreover, the clinicopathological characteristics, the treatment, the prognostic factors, and the mechanism of MT have not yet been well understood due to the rarity of such tumors, especially in women of reproductive age. ${ }^{13}$ Malignant transformation may develop due to the long-term presence of a non-removed MCT. ${ }^{18}$ Though the reason for this is not clear, it is postulated by some authors that the long-term presence of an MCT and squamous metaplasia of the columnar epithelium may be followed by such a malignant change. ${ }^{17}$ The involvement of the human papillomavirus (HPV) has been suggested, but it must be further investigated. ${ }^{13}$

Clinically, the tumor is usually asymptomatic, and is discovered accidentally during gynecologic investigations. ${ }^{13}$ If symptoms are present, they most commonly include increased lower abdominal distension and pain, as well as abdominal or pelvic mass. ${ }^{6}$ The symptoms most commonly develop in patients who are postmenopausal or whose tumor has ruptured or underwent a MT. ${ }^{6}$ Increased tumor size has been associated with a higher progression to MT in MCTs, and a worse prognosis due to the more aggressive disease. ${ }^{17}$ Rupture is an unusual complication of malignant MCTs, occurring in $\sim 1 \%$ to $2 \%$ of patients with SCCs in MCTs. ${ }^{19}$ Moreover, in these patients, the preoperative radiological findings may not differ much from those observed in cases of uncomplicated MCT. ${ }^{18}$

Serum tumor marker levels may be high in patients with MT in MCTs. The preoperative serum levels of SCCA are more frequently raised $(>2 \mathrm{ng} / \mathrm{mL})$ in patients with SCC $(\sim 41.9 \%$ of the patients); as far as other markers are concerned, serum CA125, CEA, CA19-9 and macrophage-colony stimulating factor have been found to be elevated in $59.1 \%, 65.0 \%, 64.7 \%$, and $71.0 \%$ of patients with SCC in MCT respectively. ${ }^{20} \beta$-human chorionic gonadotropin and AFP are frequently secreted, and may suggest individual tumor subtypes. ${ }^{21}$ In the case of an immature teratoma, the levels of AFP may be elevated. while those of hCG and lactic dehydrogenase are normal. ${ }^{21} \mathrm{An}$ elevated AFP with or without hCG in a young female with an ovarian mass suggests malignant ovarian germ-cell tumors. ${ }^{21}$ Although these markers are nonspecific, they can provide prognostic information, so quantitative hCG, AFP, lactic dehydrogenase, and CA125 should be measured preoperatively. ${ }^{21}$ However, MT is usually diagnosed by definitive histopathologic examination of the surgical sample. ${ }^{10}$

The authors report a case of a sarcomatoid SCC arising in an ovarian cystic teratoma in a young woman, asymptomatic, with a mass on the right ovary, with sonographic aspects that raised the suspicion of ovarian teratoma. In most series, the median age at the diagnosis of MT of an MCT is 54-61.5 years, ${ }^{3}$ and the most common symptoms are abdominal pain, palpable mass and abdominal distension; but some people may be asymptomatic at diagnosis. ${ }^{22}$ In some studies, ${ }^{23}$ an MCT with a diameter $>100 \mathrm{~mm}$ is associated with increased risk of malignancy. In our case, the tumor size was $100 \mathrm{~mm}$, with a benign classification according to the IOTA simple rules. ${ }^{16}$ The preoperative serum levels of tumoral markers are more frequently raised. ${ }^{20}$ In the case herein reported, all tumoral markers were at normal levels.

To the best of our knowledge, in the ovary, sarcomatoid carcinoma has only been reported as mural nodules in epithelial malignant tumors, ${ }^{24,25}$ borderline tumors, ${ }^{26,27}$ solid tumors, ${ }^{12}$ cystic neoplasms, and in teratomas. ${ }^{28}$ Spindle-cell (sarcomatoid) carcinoma is the one SCC variant in which the application of immunohistochemistry may be of value. ${ }^{11}$ If the surface epithelium is present, it serves as a good internal control, but it is frequently lost. ${ }^{11}$ The individual spindle 
neoplastic cells react variably, although most sensitively and reliably with keratin, epithelial membrane antigen, and cytokeratin-18 (CK18). ${ }^{11}$ Unfortunately, only $\sim 70 \%$ of cases will yield any epithelial immunoreactivity. ${ }^{11}$ Several other mesenchymal markers can be identified focally, including smooth muscle actin, muscle-specific actin, and rarely, S100 protein. ${ }^{11}$ This phenotypic plasticity is expressed by a loss of intercellular cohesion, elongation of the cells, loss of basement membrane, production of connective tissue (collagen), and invasion into the stroma. ${ }^{11}$ This type of lineage is to be expected in a tumor that has demonstrated sarcomatoid transformation to the degree observed in SCSCs. ${ }^{11}$ In this case, the immunohistochemical panel favored the diagnosis of SCSC. The differential diagnosis for any spindle-cell tumor is most challenging, ${ }^{11}$ and it includes several benign and malignant processes, such as fibromatosis, leiomyoma, fibrosarcoma, malignant fibrous histiocytoma, leiomyosarcoma, rhabdomyosarcoma, and angiosarcoma. ${ }^{11}$ The sarcomas are characterized by the presence of malignant mesenchymal elements. ${ }^{11}$ Carcinosarcoma is a mixed Müllerian tumor (MMT), and it is characterized by the presence of both carcinomatous and sarcomatous components. ${ }^{11}$ Moreover, the case herein reported shows that findings of malignant spindle-cell proliferation do not imply that this entity is a sarcoma or a malignant MMT. Additionally, careful tissue sampling and immunohistochemical analysis to distinguish these different entities is mandatory.

In the literature recommendations, the standard primary treatment should consist of bilateral salpingo-oophorectomy, total hysterectomy and comprehensive surgical staging (peritoneal washing, omentectomy, appendectomy, peritoneal biopsies, and pelvic and para-aortic lymphadenectomy) in early stages of the disease, and optimal cytoreductive surgery in advanced stages of the disease. ${ }^{10}$ Unilateral salpingo-oophorectomy associated with comprehensive surgical staging can be taken into consideration in young women with early-stage disease wishing to preserve fertility, but few data are currently available in the literature about this conservative approach. ${ }^{9}$ The spillage of cyst content should be always avoided, and the surgical removal must be performed with an endoscopic retrieval bag. ${ }^{10}$ If spillage does occur, the surgeon must carry out an accurate peritoneal washing with large amounts of warm fluid. ${ }^{8}$ After comprehensive surgical staging, patients with stage-la tumors can undergo only clinical surveillance, whereas chemotherapy is warranted for those with more advanced diseases. ${ }^{8,19}$ Platinum-based chemotherapy has been frequently used in the first-line treatment. ${ }^{8}$ Chemotherapy seems to be less effective in SCC in MCTs than in the common epithelial ovarian cancers. ${ }^{8,19}$ The role of radiotherapy remains unclear. Due to the limited number of cases for analysis, it was difficult to make definite conclusions with regards to the appropriate adjuvant radiotherapy and chemotherapy for this disease. ${ }^{13}$

In the literature review, the survival outcome of patients with MT in MCTs depends on the stage at diagnosis. ${ }^{13}$ Although the application of the International Federation of Gynecology and Obstetrics (Fédération Internationale de Gynécologie et d'Obstétrique, FIGO) staging to SCCs in MCTs does not clearly relate to the graduated outcome of the disease, there are reports of patients with FIGO stages II to IV having a lower probability of long-term survival than patients with stage-I diseases. ${ }^{3,13}$ Age, tumor size, clinical stage, histologic differentiation, capsular invasion, and the presence of vascular invasion can provide valuable information for the prediction of the survival of patients with SCCs in MCTs. ${ }^{3,13}$ The early diagnosis of the MT before invasion or metastasis is important for the treatment. A large ovarian mass suspected to be a mature teratoma should be more carefully managed in older patients. ${ }^{13}$ Recent studies showed that a tumor size $\geq 150 \mathrm{~mm}$ appeared to be strongly associated with aggressive diseases, and generally spreads by direct invasion and peritoneal implantation rather than by metastasis to the regional lymph nodes.,20 Squamous cell carcinomas of the ovary spread transmurally with extensive local invasion, which is different from common ovarian tumors, and the overall 5-year survival rate is $\sim 50 \%^{3,20}$

In many organs such as the kidney, the breast, and the urinary bladder, sarcomatoid carcinomas are neoplasms, with poor prognosis. ${ }^{12}$ As a consequence of the relative rarity and diagnostic heterogeneity of these tumors, it has proven difficult to properly predict their behavior and to determine the optimal management. ${ }^{11}$ Although it was first thought to carry an invariably unfavorable prognosis, recent data indicate that this does not apply to stage-Ia tumors. ${ }^{11}$ Our findings are consistent with the aforementioned data. In the case herein reported, at diagnosis, the neoplasm was located within the ovary, without invasion of surrounding tissue and lymph node metastases. The patient chose to preserve fertility, and surgical staging did not reveal tumor alterations, and the tumor was classified as stage I. No further treatments were administered. The patient remained asymptomatic, and showed no evidence of local recurrence or systemic disease after 3 years of clinical surveillance.

\section{Conclusion}

In conclusion, the MT of MCTs in young women is very rare, and its preoperative diagnosis is difficult. It should be suspected when the patient has a large ovarian mass $(\geq 150 \mathrm{~mm}$ ) and direct invasion or metastasis should be investigated. Moreover, the case herein reported shows that findings of spindle-cell proliferation do not imply that this entity is a sarcoma or a malignant MMT. Additionally, careful tissue sampling and immunohistochemical analysis to distinguish these different entities is mandatory. There is an ongoing debate on the best management practices for this disease entity, and the benefits of early diagnosis and intervention cannot be more emphasized for a better prognosis.

Conflict of Interests

The authors have none to disclose.

\section{References}

1 Abhilasha N, Bafna UD, Pallavi VR, Rathod PS, Krishnappa S. A review of squamous cell carcinoma arising in mature cystic teratoma of the ovary. Indian J Cancer 2016;53(04):612-614. Doi: 10.4103/0019- 509X.204763 
2 Boussios S, Attygalle A, Hazell S, et al. Malignant ovarian germ cell tumors in postmenopausal patients: the Royal Marsden experience and literature review. Anticancer Res 2015;35(12):6713-6722

3 Dos Santos L, Mok E, Iasonos A, et al. Squamous cell carcinoma arising in mature cystic teratoma of the ovary: a case series and review of the literature. Gynecol Oncol 2007;105(02):321-324. Doi: 10.1016/j.ygyno.2006.12.008

4 Slavin G. Anderson's pathology. J Clin Pathol. 1985;38(12):1408

5 Templeman CL, Fallat ME, Lam AM, Perlman SE, Hertweck SP, O'Connor DM. Managing mature cystic teratomas of the ovary. Obstet Gynecol Surv 2000;55(12):738-745

6 Powell JK. Benign adnexal masses in the adolescent. Adolesc Med Clin 2004;15(03):535-547

7 Gadducci A, Guerrieri ME, Cosio S. Squamous cell carcinoma arising from mature cystic teratoma of the ovary: A challenging question for gynecologic oncologists. Crit Rev Oncol Hematol 2019;133:92-98. Doi: 10.1016/j.critrevonc.2018.10.005

8 Wen KC, Hu WM, Twu NF, Chen P, Wang PH. Poor prognosis of intraoperative rupture of mature cystic teratoma with malignant transformation. Taiwan J Obstet Gynecol 2006;45(03):253-256. Doi: 10.1016/S1028-4559(09)60236-9

9 Araujo IB, Pinheiro MV, Zanvettor PH, Studart EJ, Filho DF, Coupland SE. High Frequency of Malignant Transformation of Ovarian Mature Teratoma into Squamous Cell Carcinoma in Young Patients in Northeast Brazil. Int J Gynecol Pathol 2016;35(02): 176-184. Doi: 10.1097/PGP.0000000000000225

10 Feng X, Xu L. Rare case of squamous cell carcinoma arising in a recurrent ovarian mature cystic teratoma of a young woman: A case report and review of the literature. Medicine (Baltimore) 2018;97(20):e10802. Doi: 10.1097/MD.0000000000010802

11 Thompson LDR. Squamous cell carcinoma variants of the head and neck. Curr Diagn Pathol 2003;9:384-396. Doi: 10.1016/S0968-60 53(03)00069-3

12 Giordano G, Berretta R, Silini E. Primary pure spindle cell carcinoma (sarcomatoid carcinoma) of the ovary: A case report with immunohistochemical study. Diagn Pathol 2016;11(01):70. Doi: 10.1186/s13000-016-0521-3

13 Iwahashi N, Deguchi Y, Horiuchi Y, et al. Live birth following laparoscopic fertility-sparing surgery for papillary thyroid carcinoma arising from mature ovarian cystic teratoma: A case report. Mol Clin Oncol 2018;9(06):613-616. Doi: 10.3892/mco.2018.1743

14 Lataifeh I, Abdel-Hadi M, Morcos B, Sughayer M, Barahmeh S. Papillary thyroid carcinoma arising from mature cystic teratoma of the ovary. J Obstet Gynaecol 2010;30(08):884-886. Doi: $10.3109 / 01443615.2010 .511725$

15 Rowe JS, Makar G, Holdbrook T, Germaine P. Squamous cell carcinoma arising in a partially ruptured giant mature cystic teratoma: A case report. Radiol Case Rep 2018;14(01):97-102. Doi: 10.1016/j.radcr.2018.09.029

16 Timmerman D, Van Calster B, Testa A, et al. Predicting the risk of malignancy in adnexal masses based on the Simple Rules from the
International Ovarian Tumor Analysis group. Am J Obstet Gynecol 2016;214(04):424-437. Doi: 10.1016/j.ajog.2016.01.007

17 Rathore R, Sharma S, Agarwal S. Malignant transformation in mature cystic teratoma of the ovary: a retrospective study of eight cases and review of literature. Przegl Menopauz 2018;17(02): 63-68. Doi: 10.5114/pm.2018.77304

18 Chiang AJ, Chen MY, Weng CS, et al. Malignant transformation of ovarian mature cystic teratoma into squamous cell carcinoma: a Taiwanese Gynecologic Oncology Group (TGOG) study. J Gynecol Oncol 2017;28(05):e69. Doi: 10.3802/jgo.2017.28.e69

19 Suzuki M, Tamura N, Kobayashi H, Ohwada M, Terao T, Sato I. Clinical significance of combined use of macrophage colonystimulating factor and squamous cell carcinoma antigen as a selective diagnostic marker for squamous cell carcinoma arising in mature cystic teratoma of the ovary. Gynecol Oncol 2000;77 (03):405-409. Doi: 10.1006/gyno.2000.5784

20 Hackethal A, Brueggmann D, Bohlmann MK, Franke FE, Tinneberg HR, Münstedt K. Squamous-cell carcinoma in mature cystic teratoma of the ovary: systematic review and analysis of published data. Lancet Oncol 2008;9(12):1173-1180. Doi: 10.1016/ S1470-2045(08)70306-1

21 Brown J, Friedlander M, Backes FJ, et al. Gynecologic Cancer Intergroup (GCIG) consensus review for ovarian germ cell tumors. Int J Gynecol Cancer 2014;24(09, Suppl 3):S48-S54. Doi: 10.1097/ IGC.0000000000000223

22 Tseng CJ, Chou HH, Huang KG, et al. Squamous cell carcinoma arising in mature cystic teratoma of the ovary. Gynecol Oncol 1996;63(03):364-370. Doi: 10.1006/gyno.1996.0337

23 Yamanaka Y, Tateiwa Y, Miyamoto H, et al. Preoperative diagnosis of malignant transformation in mature cystic teratoma of the ovary. Eur J Gynaecol Oncol 2005;26(04):391-392

24 Czernobilsky B, Dgani R, Roth LM. Ovarian mucinous cystadenocarcinoma with mural nodule of carcinomatous derivation. A light and electron microscopic study. Cancer 1983;51(01):141-148. Doi: 10.1002/1097-0142(19830101)51:1<141:aid-cncr2820510 $128>3.0 . \mathrm{co} ; 2-7$

25 Hillesheim PB, Farghaly H. Anaplastic spindle cell carcinoma, arising in a background of an ovarian mucinous cystic tumor: a case report with clinical follow up, review of the literature. Int J Clin Exp Pathol 2010;3(08):808-811

26 Andrews TD, Dutton PM, Beattie G, Al-Nafussi A. Sarcomatoid carcinoma arising within a serous borderline ovarian tumour: a case report and practical approach to differential diagnosis. Histopathology 2008;52(02):233-238. Doi: 10.1111/j.13652559.2007.02864.x

27 Ghosh P, Saha K, Bhowmik S. Sarcoma-like mural nodule in a borderline mucinous tumor of the ovary: A rare entity. J Midlife Health 2014;5(04):192-194. Doi: 10.4103/0976-7800.145168

28 Czernobilsky B, Rotenstreich L, Lancet M. Ovarian dermoid with squamous carcinoma-pseudosarcoma. Arch Pathol 1972;93(02): $141-144$ 